\title{
Are fishing communities another most-at-risk- population? Results of a community-based study along Lake Victoria, Uganda
}

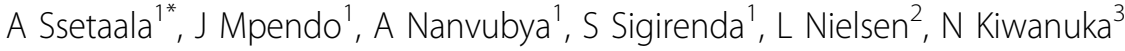 \\ From AIDS Vaccine 2012 \\ Boston, MA, USA. 9-12 September 2012
}

\section{Background}

A recent study reported HIV prevalence of $28.8 \%$ among high risk persons in fishing communities (FC) of Uganda, indicating that FC may be another most-at-risk-population (MARP). However, these findings do not reflect the population-based HIV prevalence in FC. We conducted a community-based study to determine the population representative HIV prevalence and incidence among FC along Lake Victoria shores, Uganda.

\section{Methods}

Community-wide mapping and census of households in 8 fishing communities was conducted. A computer-based random sample of 2200 participants aged 18-49 years was selected for interviewing by same-sex interviewers using a semi-structured questionnaire. Blood was collected for HIV serology using rapid HIV tests as per the national algorithm.

\section{Results}

We interviewed 2,192 (99.6\%) participants, of whom fifty percent were females, median age 29 years, IQR 24-35 years and $82 \%$ had stayed in the communities for at least a year.

HIV prevalence was $26.7 \%$, higher among females than males [ $32.6 \%$ vs. $20.8 \%, \mathrm{p}<0.01, \mathrm{OR}=0.5]$, those who were single [ $34.7 \%$ vs. $27.8 \%, \mathrm{p}<0.01, \mathrm{OR}=1.4]$, those with $>5$ lifetime sexual partners [ $32 \%$ vs. $21 \%, \mathrm{p}<0.01, \mathrm{OR}=1.7]$, with no formal education $[39.2 \%$ vs. $25.5 \%, \mathrm{p}<0.01$, $\mathrm{OR}=0.5]$, reported alcohol use in previous 3 months [32\% vs. $20.8 \%, \mathrm{p}<0.01, \mathrm{OR}=1.8$ ], alcohol use before sex
[34\% vs. $21 \%, \mathrm{p}<0.01, \mathrm{OR}=0.5]$ and used illicit drugs [33\% vs. $25.6 \%, \mathrm{p}<0.01, \mathrm{OR}=0.7]$.

HIV prevalence varied by occupation, highest among sex workers $(66.7 \%)$, boat makers $(50 \%)$, government employees (43\%), bar owners (37.6\%) and bar attendants (36.4\%), $[\mathrm{p}<0.01]$. Prevalence increased with age [p<0.01] and was not associated with consistent condom use [26.8\% vs. $26.4 \%, \mathrm{p}=0.45]$.

\section{Conclusion}

FC in Uganda have a disproportionately high HIV prevalence compared to the national average of $6.7 \%$. Our prevalence estimate was comparable to that reported among high risk FC. Prevention efforts towards reducing HIV prevalence in these communities are needed, and such populations may be considered for future HIV prevention trials.

\section{Author details}

${ }^{1}$ UVRIIIAVI HIV Vaccine Program, Entebbe, Uganda. ${ }^{2}$ International AIDS Vaccine Initiative(IAVI), New York, USA. ${ }^{3}$ Makerere University College of Health Sciences School of Public Health, Kampala, Uganda.

Published: 13 September 2012

doi:10.1186/1742-4690-9-S2-P216

Cite this article as: Ssetaala et al: Are fishing communities another most-at-risk-population? Results of a community-based study along Lake Victoria, Uganda. Retrovirology 2012 9(Suppl 2):P216.

'UVRI-IAVI HIV Vaccine Program, Entebbe, Uganda

Full list of author information is available at the end of the article

C 2012 Ssetaala et al; licensee BioMed Central Ltd. This is an Open Access article distributed under the terms of the Creative Commons 